\title{
ADMINISTRATIVE INNOVATION IN LOCAL GOVERNMENT BUREAUCRACIES: CASE STUDY OF THESABAN, PHETCHABUN PROVINCE, THAILAND
}

\author{
Suebsawad Vutivoradit \\ Keratiwan Kalayanamitra \\ Suan Sunandha Rajabhat University, Bangkok, Thailand \\ Sunhanat Jakkapattarawong \\ Pathumthani University, Pathumthani, Thailand
}

Thai public sector always described as a highly centralized system, with an inflexible hierarchical structure and high levels of formal relationships channeling its communications through public enterprises and institutions. Even establishing the local administration system as an approach of decentralization, is still highly connected and governed by the central government. On the other hand, innovation in public sector studies and application in last two decades gained much interest from scholars, practitioners and even leaders and policy makers as an approach to enhance public sector efficiency and effectiveness. Accordingly, this study aims to explore innovation in the public sector in Thesaban Mueang Phetchabun Thailand.

It can represent the public sector in Thailand on a larger scale. The study evaluates the laws, structures and dynamics that constitute the framework of the local administration system. Furthermore, it explores the main constraints on innovation within the system. To develop and support the argument, which emerges from the literature review, this study employs qualitative research methods, namely interviews, as a method to collect data from various informants working in and/or with the public sector.

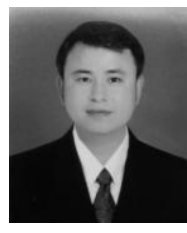

Suebsawad Vutivoradit

works in College of Innovation and management, Suan Sunandha Rajabhat University,

Bangkok, Thailand, member of evaluation team

Research interests : local administration, political strategy, national politic, community, problems pf democracy

E-mail: $\underline{\text { seubsawad_vu@ssru.ac.th }}$

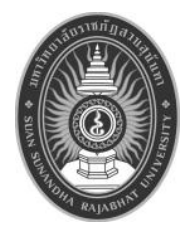

Keratiwan Kalayanamitra

works in College of Innovation and management, Suan Sunandha Rajabhat University,

Bangkok, Thailand, member of evaluation team

Research interests : local administration, political history

E-mail: keratiwan_ka@ssru.ac.th

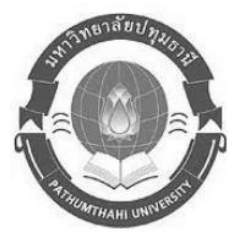

Sunhanat Jakkapattarawong

works in Pathumthani University, Pathumthani, Thailand, Thailand,

department of political science

Research interests : local administration, political history 


\section{ADMINISTRATIVE INNOVATION IN LOCAL GOVERNMENT}

The results of the study indicated that the innovative administration implemented by local administrative organization was distinct and different from each other based on its own main mission. Specifically, while the top-down innovation was implemented by big local administrative organizations. The initiating process comprised three steps. First, there were meetings among involved personnel. After that, there was an attempt to network with external organizations. Finally, there were processes of monitoring and follow-up evaluation as well as the establishment of learning center. Concerning factors in relation to initiating processes, they comprised six factors which included leadership for change, corporate culture, knowledge and competency of practitioners, public participation, supports from external organizations, and social capitals.

Keywords: administrative innovation; local government; bureaucracies

\section{Introduction}

In its journey through modern history, public administration system in developed countries has witnessed many reforms; some of which were minor, others of which were major, whilst a few were radical. From the nineteenth century onwards, Max Weber has been considered one of the main figures who contributed greatly in founding and establishing the traditional public administration system, which was built with many characteristics, mainly bureaucracy and hierarchy (Denhardt \& Denhardt, 2009).

During the twentieth century, the public administration system, influenced by many theories, underwent important changes. These included Taylor's invention scientific management principles, and theories of organizational behavior from the Human Relations Schools as founded by Elton Mayo. In addition, during the early 1980s and with the emergence of neoliberalism as an ideology in social and political life, the public administration system experienced a radical change. Most governments in developed countries transformed its usual administration system into the new public management system (NPM). The NPM led to many big changes in the public sector, such as the downsizing of government, minimizing its scope from being an administrator of everything into rather being a manager and contractor, thus reducing its budget. The marketing of government and privatization became the norm (Denhardt \& Denhardt, 2009).

Although shifting into the NPM system was marked as a radical and noticeable advancement in the public sector in developed countries, the changes were subject to growing criticism regarding the devaluing of citizens, wherein they became increasingly treated as customers. Such criticism paved the way to reinvent the new public governance (NPG) system, which is distinguished by a citizen-centered orientation, considering citizens to be co-producers, thus sharing the responsibility of the decision-making process through collaborative networks.

All of these minor, major and radical reforms mentioned above were innovations, or creative ideas, yet they occurred randomly and in a discrete manner. Therefore, scholars and practitioners were urged to think how they could convert these inventions into innovations, how they could be defined as new ideas to be implemented successfully in a continuous process, and how to make the innovation process a core concept in any public sector organization (Bessant, 2003).

Innovation is therefore a new paradigm in the public sector. Although lacking resources (Bloch \& Bugge, 2013; Bommert, 2010), innovation has received increasing interest over the last few decades among scholars, researchers and practitioners. More recently, it has become 
part of the top agenda of many states' public agencies (Klas et al, 2015). Although the public sector has undergone a great deal of innovation throughout its history, as mentioned earlier, it is still far behind the private sector (Albury, 2005). The main reason why the private sector is described as innovative relates to its intrinsic value, which is profit. The highly competitive environment of the private sector forces it to be as innovative as possible in order to survive and gain profits (Prapysatok \& Jakkapattarawong, 2018).On the other hand, the monopoly conditions (Kattel, 2015), lack of incentives and avoidance of failure by elected officials (Bloch \& Bugge, 2013), all of which characterize the public sector, lead to a dampening of the internal drivers of innovation.

With the context of Thai society in accordance with democracy at present, there is a division of government into 3 parts: central Regional and local.

For local government, it is considered a form of public administration which is the basis of national development and democracy in Thailand that is closest to the people. Especially in the local community with different social, cultural and living conditions and natural resources if there is a hope of relying on the central government as a whole to take care of the people all over the country would not be able to meet the needs or solve problems thoroughly. And they meet the needs of people in each area Local administrative organizations are therefore very important to the development. And they went to fix the problem immediately by giving the community the right to decide to carry out various local missions, giving priority to learning and practice local governance in a democratic form with participation by local community. (Phuangngam, 2007, 11).

All of these initiatives have been launched recently, placing an additional burden on the government to address innovation in its strategies and programs so as to achieve its objectives. Hence, this research will take a leading step towards studying the environment of the public administration

Accordingly, the purpose of this research is to make an additional contribution to previous efforts made which aimed to enhance and promote innovation in the Thai public sector. This study aims to explore the public sector in Thailand in order to find out the extent to which it permits innovation. In addition, it aims to search for experiences of innovation, if any, within the public sector in Thailand, before discussing them in relation to recent advances in contemporary understandings of innovation.

\section{Literature review}

\section{Innovation}

One of the early scholars who mentioned innovation in the context of the public sector was (Schumpeter, 1939) with his famous theory of "Business Cycles" and evolutionary change, in mentioning how "the theory of evolutionary change adapted to the economic sphere, of a much larger theory which applies to change in all spheres of social life, science and art included." During the period from 1960 - 1990, whilst much effort was made to describe and theorize innovation in the private sector, some scholars endeavored to conceptualize innovation in both the public and private sector in general, influenced both by the norms of scientific management principles as invented by Taylor and the ideal model of bureaucracy as invented by Weber that was considered appropriate for the private and public sectors alongside one another (Kattel, 2015). 


\section{ADMINISTRATIVE INNOVATION IN LOCAL GOVERNMENT}

Arundel \& Huber (2013) found that Roessner conducted the first documented explicit study on public sector innovation in 1977. Despite the scarcity of research on public sector innovation, they noticed that case studies overshadowed almost all academic research until the early 2000s. In addition, they identified just eighteen research studies, which made use of fifteen wide-ranging sources of data and surveys.

Gow (2014) also demonstrated the dearth of public sector innovation publications. He found that it constituted just 1.4\% of all publications among 316 million references in a Google search conducted in 2013. However, when examining the literature so as to review what academics and practitioners have published on innovation, one can find that there is a wide spectrum of views and perceptions even regarding major concepts of innovation.

Phuangam (2010, p.79) explained Innovation of local administrative organizations means inventing, improving and developing new things to happen in local administrative organizations. The literature therefore contains a diverse spectrum of views among scholars concerning many issues, including the definition of innovation, its boundaries, types of innovation, the scale of innovation, and the classification of innovation. These topics will now be introduced in the following sections.

\section{Methodology}

Qualitative Research Method by using in-depth interview with key informants and nonparticipant's observation were used in this study. The procedure of this research was as follow:

1. Populations and Samples

Populations and Samples in this study composed of government agencies, stakeholder, and community leader/resident in Thesaban, Phetchabun, Thailand. Criteria-based selection of 15 sampling was used to collect the data.

2. Instrument Development and Data Collection

Semi-Structural interview and in-depth interview by observation with sound and camera recordingwas used to collect the data

3. Data Analysis

Triangulation was used to collect the different data and collectors (Jantaravanich, 2556, 32-34). Data was analyzed by inductive reasoning and presented in descriptive method.

\section{Results}

\section{Characteristics of administrative innovation}

For the study of the characteristics of administrative innovation in the local administrative organization, there are studies based on the innovation framework of public administration. Which the researchers divided into 5 categories according to the determination of the type of innovation, public administration by the bureaucratic development committee Which have been applied to this research are 1) policy and strategy 2) product and service 3) service delivery model 4) process and organization management and 5) service Process interaction Which the study found Each local government organization will have different administrative innovation depending on the distinguished management innovation of the local government organization in each mission of the organization that has the process of initiative and development in the context of There are 
differences therefore resulting in different aspects of innovation management.

\section{Source of administrative innovation}

The origin of administrative innovation for this study found that the origin of innovation may be caused by high-level agencies or executives with the characteristics that come into the top-down level. TDI (Top down innovation) or the bottom up on the BUI (Bottom up innovation), which comes from the needs of the people.

The results of the study that came the administrative innovation of the local government organization. There are different sources of innovation depending on the nature of the administrative innovation of the local government organization in each mission of that organization.

For the local administrative organization of Thailand, such as Thesaban, Phetchabun. There is a source of management innovation in the top-down level. TDI (Top down innovation)

\section{The process of creating administrative innovation}

The study of the process of creating innovation in the administration of local administrative organizations, the results of the study of the management innovation, it can be seen that the characteristics and origin of the innovation will be different according to the organization's mission, affecting the innovation process. Management of local administrative organizations to be different for management innovations that are originated in the top to bottom levels, TDI (Top down innovation) will have the process of creating innovation. The management consists of 4 steps, consisting of 1) management meeting 2) Joint meetings of the management with the operator 3) Creating a network with external agencies and 4) Monitoring and evaluation

\section{Factors related to the process of creating innovation in management}

The factors related to the process of creating innovation, management includes

1) Transformational leadership. It has 4 important elements: 1) ideological influence 2) motivation 3) intellectual stimulation 4) individualization. From the study, it was found that the administrators were very important to the innovation of the local government organization. Which must be a person with a vision, a clear policy to encourage subordinates There is a regular consultation meeting. Including the development of the potential of the personnel to be able to perform the assigned tasks more efficiently

2) Corporate culture. According to studies, it has been found that culture of work focuses on work combined with a culture that focuses on leadership. Most of the operations in the local government organization, there will be a brother-in-law. There are generosity, mutual support, informal communication, discussion, exchange of information at work all the time.

3) Knowledge and competency of the practitioner. According to studies, it has been found that practitioner has sufficient knowledge and ability to perform the job by receiving continuous skills, knowledge and ability to work. Most of the work skills were combined with academic knowledge: coordinating, integrating, working with local communities and with determination.

4) Social capital.The result of study which found that social capital consists of Trust, 


\section{ADMINISTRATIVE INNOVATION IN LOCAL GOVERNMENT}

trustof Community cooperation norms and network of social relationships by working with trust including a framework for working together. In addition, the work of the organization also creates a network with various external agencies in order to create an integrated work effectively together.

5) Public participation. According to studies, it has been found that participation of the people participates in cooperation in working with local government organizations effectively. By having a role and participating in various activities, including joint thinking, co-operation, planning in the activities of local government organizations as well.

6) Support from external agencies. According to studies, it has been found that Support from external agencies, providing support in the areas of knowledge and coordination of most collaborations. But in some areas, support from external agencies has not been supported as it should be. In the part that most of the participants have come to join in academic support And joined as a working network in order to work effectively.

\section{Conclusions}

Administrative innovation in local government bureaucracies: case study in Thesaban, Phetchabun. The results of the study consist of the innovative administration implemented by local administrative organization was distinct and different from each other based on its own main mission.

Specifically, while the top-down innovation was implemented by big local administrative organizations. The initiating process comprised three steps.

First, there were meetings among involved personnel. After that, there was an attempt to network with external organizations.

Finally, there were processes of monitoring and follow-up evaluation as well as the establishment of learning center. Concerning factors in relation to initiating processes, they comprised six factors which included leadership for change, corporate culture, knowledge and competency of practitioners, public participation, supports from external organizations, and social capitals.

\section{Suggestion}

1. Department of Local Administration should accelerate the development of local leaders and workers in local government organizations to have continuous self-development.

2. The Department of Local Administration should establish policies for the dissemination of innovations of local government organizations to the local government organization continuously.

3. The Public Sector Development Commission (GPA) should determine the type of administrative innovation. For local administrative organizations specifically, if there is a clear management innovation, it will result in the application of such type of innovation to the local government organization effectively.

\section{Acknowledgement}

The author would like to thank the Research and Development Institute, Suan Sunandha Rajabhat University, Bangkok, Thailand for financial support. 


\section{References:}

Albury D. (2005). Fostering innovation in Public Services. Public Money \&Management, 25:1, 5156.

Arundel, A., \& Huber, D. (2013). From too little to too much innovation? issues inmeasuring innovation in the public sector. Structural Change andEconomic Dynamics, 27, 146-159.

Bessant, J. R. (2003). High-involvement innovation: Building and sustaining competitive advantage through continuous change. Chichester: Wiley.

Bloch, C., Bugge, M. (2013). Public sector innovation-From theory to measurement. Structural Change and Economic Dynamics, (27), 133-145.

Bommert, B. (2010). Collaborative innovation in the public sector. International Public Management Review, 11, 15-33.

Charoensethom, S. (2008). Guidelines for innovation in the organization. Ramkhamhaeng Journal, 25 (4), 130-140.

Denhardt, R., Denhardt, J. (2009). Public administration: An action orientation. Belmont, CA: Thomson/Wadsworth.

Gow, J. I. (2014). Public sector innovation theory Revisited. The Innovation Journal,19(2), 1.

Jantaravanich, S. (2013). Data analysis in qualitative research, Bangkok: Chulalongkorn University Press.

Kattel, R. (2015). What would max weber say about public-sector innovation? Journal of Public Administration and Policy, 8(1), 9-19.

Klas P., Johan L., Håkan W., (2015). Agencies, it's time to innovate! International Journal of Quality and Service Sciences, 7, 1. $34-49$.

Phuangngam, K. (2007). Thai local government: the main textbook. Conducting a Bachelor of Public Administration course Local government branch Academic City, Local Government, Thailand. Bangkok: Extranet.

Phuangngam, K. (2010). Synthesis and removal of lessons on local innovation and public service of local government organizations (Master of mission management Transfer) Office of the Distribution Commission Power to the administrative organization Local area. Research Report. Bangkok: Prime Minister's Office.

Prapysatok, S., Jakkapattarawong, S. (2018). The participation of the community in cultural and environmental conservation for sustainable tourism. Case study in Samphanthawong District Bangkok. Research report, Research and Development Institute, Suan Sunandha Rajabhat University.

Paper submitted

Paper accepted for publishing

Paper published online
18 February 2019

16 April 2019

25 June 2019 